Sharif University of Technology
Scientia Iranica
SCIENTIA
I RAN ICA
Transactions A: Civil Engineering
www.scientiairanica.com

\title{
Seismic performance of reinforced concrete building in Guwahati city, northeast India
}

\author{
S. Ghosh and S. Chakraborty* \\ Department of Civil Engineering, Indian Institute of Engineering Science and Technology, Shibpur 711103, India.
}

Received 2 November 2015; received in revised form 1 March 2016; accepted 17 May 2016

\author{
KEYWORDS \\ Concrete building- \\ frame; \\ Northeast India; \\ Ground motion \\ simulation; \\ Nonlinear dynamic \\ analysis; \\ Random pushover; \\ Seismic fragility.
}

\begin{abstract}
The seismic risk of reinforced concrete building frame located in the Guwahati City of northeast India is evaluated. To do so, we first conduct a site-specific probabilistic seismic hazard analysis to obtain hazard curve and implement proper selection of ground motion records for nonlinear time history analyses (NLTHA). Subsequently, the NLTHA of the building frame is performed to obtain the drift demand for any particular ground motion level. As the recorded accelerograms in the region are limited, the synthetic and artificial ground motion data are also generated to supplement the data base. Thereafter, the probabilistic structural capacity parameters at various limit states are obtained from random pushover analyses. Based on the knowledge of seismic hazard, demand, and capacity parameters, fragility curves are obtained corresponding to different structural performance levels. The annual probability of failure of the representative example frame is also estimated. The results of the seismic risk analysis indicate that a medium-rise reinforced concrete building frame in the study area with moderate fundamental period is most likely to perform beyond its elastic range. However, such structures designed according to the Indian codes are expected to be sufficient enough to prevent life-threatening risk and complete collapse.

(C) 2017 Sharif University of Technology. All rights reserved.
\end{abstract}

\section{Introduction}

A probabilistic framework is necessary to seismic performance assessment of structures to accommodate the inherent randomness in ground motion due to earthquake and uncertainty involved in structural parameters. The Performance-Based Earthquake Engineering (PBEE) for quantifying seismic risk of structures, considering the uncertainties in ground motion characteristics, structural response, physical damage, and economic and human losses, is worth mentioning in this regard [1]. The approach mainly consists of four successive stages: hazard analysis, structural analysis, damage analysis, and loss analysis. The damage analy-

*. Corresponding author. Tel.: 913326684561

E-mail addresses: gh.swarup@gmail.com (S. Ghosh);

schak@civil.iiests.ac.in (S. Chakraborty) sis is generally referred to as Seismic Fragility Analysis (SFA) where the structural damage levels are identified by constructing fragility curves. It basically represents the probability of exceeding a structural performance level of the demand parameter corresponding to a target hazard level. The loss analysis then computes the amount of economic losses and casualties due to an earthquake. Due to the increasing application of PBEE, the SFA is being accepted as an important tool to assess the performance of structures during future earthquakes.

The present study deals with performance-based seismic risk assessment of concrete building frame located in Guwahati City, northeast (NE) India: one of the six most seismically active regions of the world [2]. The region has experienced nineteen large earthquakes ( $M \geq 7$ ) during the last hundred years [2] including the great Shillong Earthquake (1897, $M=8.7$ ) and Assam- 
Tibet Earthquake $(1950, M=8.7)$, and it is placed in the highest hazard zone by the seismic zonation map of the country [3]. Furthermore, there has been a phenomenal increase in the population density and infrastructural developments in the region increasing the vulnerability of human population and structures to the earthquakes. Therefore, realistic seismic risk assessment of the existing structures in the region is imperative for any hazard mitigation measure. The present study deals with performance-based seismic risk assessment of the existing structures in the $\mathrm{NE}$ region of India.

Performance-based seismic risk assessment requires Probabilistic Seismic Hazard Analysis (PSHA) to obtain the hazard curve which provides the probability of exceeding various ranges of ground motion intensity measures. Seismic risk assessment also largely hinges on proper evaluation of structural demand parameters through nonlinear time history analyses (NLTHA). To do so, proper selection of ground motion records based on the most vulnerable magnitude distance combination for a specific hazard level is important. These are typically determined from the disaggregation of PSHA. Though some studies are available on PSHA of the region $[4,5]$, site-specific information is not readily available. Moreover, these regional-level PSHA studies do not provide enough information for hazard disaggregation as required for the present study.

In the present study, seismic performance of a typical midrise building, i.e. seven-storey concrete frame building considered to be located in Guwahati city, NE India (Latitude 26.2, Longitude 91.7), is examined. Accordingly, to estimate the seismic hazard curve parameters for the location, a PSHA is first carried out, and the ground motion data necessary for NLTHA of the frame are then judiciously selected. Subsequently, the NLTHA are carried out to obtain the displacement demand parameters for the example frame using a set of selected ground motion records which corresponds to the estimated hazard level of the study area. The recorded accelerograms in the study region corresponding to the target hazard level are limited. To supplement this limitation, artificial and synthetic accelerograms are generated for statistically meaningful study. The deterministic choice of threshold drift capacity may result in an overestimation of the fragility curve [6]. Hence, the probabilistic structural capacity parameters at various limit states are obtained from the random pushover analysis of the considered building frame. Subsequently, with the knowledge of the seismic hazard, demand and capacity parameters, the analytical seismic fragility is obtained and fragility curves are generated corresponding to different structural limit states. The seismic risk, i.e. the annual probability of failure of the frame, is finally estimated.

\section{Fundamentals of seismic risk analysis}

In the context of the present study, the fundamental of seismic risk analysis is to estimate the probability of exceeding a structural limit state. It is basically a time-dependent reliability analysis problem in which the limit state of interest is the difference between seismic demand and structural capacity and can be mathematically expressed as follows:

$$
Z\left(\mathbf{X}_{\mathbf{C}}, \mathbf{X}_{\mathbf{D}}, t\right)=C\left(\mathbf{X}_{\mathbf{C}}, t\right)-D\left(\mathbf{X}_{\mathbf{D}}, t\right),
$$

where $\mathbf{X}_{\mathbf{C}}$ and $\mathbf{X}_{\mathbf{D}}$ are the variables governing capacity and demand, respectively, and $t$ is the time parameter. The limit state function for seismic risk can be expresses as follows:

$$
\begin{aligned}
& Z<0 \quad \rightarrow \quad \text { Failed } \\
& Z=0 \rightarrow \text { Limiting } \\
& Z>0 \rightarrow \text { Safe }
\end{aligned}
$$

Accordingly, the seismic risk estimate is the evaluation of the probability that the limit state function will be negative which is essentially the evolution of the following integral:

$$
P_{f}=\int_{\Omega} f_{Z}(\mathbf{X}) d \Omega
$$

where $\mathbf{X}$ is an ' $n$ ' dimensional vector having variables involving seismic demand and capacity, $f_{Z}(\mathbf{X})$ is the joint probability density function (pdf) of the involved random variables, and $\Omega$ is the failure domain in the space of $\mathbf{X}$ where the limit state function is negative. The exact computation of the above is often computationally demanding. In fact, $f_{Z}(\mathbf{X})$ is hardly available in closed form. Consequently, various approximations are usually adopted to obtain the probability of reaching/exceeding different limit states of damage concerning the given building response parameter under a specific seismic intensity measure.

An excellent state-of-the-art development focusing on the seismic performance of structures that includes modelling of seismic vibration and structural analysis in probabilistic manner is notable [7]. Two basic approaches in this regard can be identified: (i) analytical approach based on probabilistic seismic demand and capacity model; (ii) simulation-based approach based on non-linear PBEE using random field theory. A conceptually straightforward, but computationally demanding, methodology is based on Monte Carlo Simulation (MCS) technique. The validity and robustness of MCS-based approach is well known [8]. However, large numbers of nonlinear dynamic analyses coupled with different frame typologies make simulation-based approach more impractical. Thus, 
the analytical seismic risk assessment, i.e. a balanced approach of accuracy and computational requirements, is more popular. The basic concept of analytical approach can be found in studies of Collins et al. [9] and subsequent ones $[10,11]$. The present work provides a comprehensive study on the analytical seismic risk assessment of concrete building frame located in the Guwahati city.

\section{Analytical seismic risk analysis}

The seismic risk of a structure at a site is given as the failure limit state probability, $P_{L S}=P[D \geq C]$, i.e. the exceedance of structural demand value $(D)$ to its capacity $(C)$. To determine $P_{L S}$ analytically, the problem of evaluating the limit state probability is decomposed into parts using the total probability theorem and introducing ground motion intensity measure as an interface variable [11]. Here, the choice of ground motion intensity measure is crucial. Seismic demands are known to be strongly correlated with the elastic spectral acceleration $\left(S_{a}\right)$ at the fundamental period of the structure, and the minimum numbers of records required to estimate the fragility parameters are also reduced when $S_{a}$ is used as the intensity measure instead of Peak Ground Acceleration (PGA) [12]. Therefore, $S_{a}$ is adopted as the intensity measure serving as interface variable. The decomposition is then obtained as follows:

$$
\begin{aligned}
P_{L S} & =P[D \geq C]=\sum_{x} P\left[D \geq C \mid S_{a}=x\right] \cdot P\left[S_{a}=x\right] \\
& =\int_{x} F_{R}(x) \cdot\left|d \lambda_{S_{a}}(x)\right|
\end{aligned}
$$

In the above integral, the first term denotes the fragility and the second term corresponds to the hazard. Thus, calculating probability of the limit state requires solution of these two terms. The first one (i.e., the fragility) represents the probability of demand exceeding capacity for a target hazard ( $S_{a}$ herein). The target hazard level can be estimated from PSHA of the location under consideration. The demand parameters are obtained by NLTHA of the structure, while the capacity parameters are obtained from capacity analysis. The resulting fragility function is usually modeled by a lognormal Cumulative Distribution Function (CDF):

$$
F_{R}(x)=\Phi\left[\frac{\ln \left(x / m_{R}\right)}{\beta_{R}}\right],
$$

where $\Phi[$.$] is the standard normal probability integral,$ $m_{R}$ is the median fragility, and $\beta_{R}$ is the logarithmic Standard Deviation (SD) or dispersion of the fragility. The second term in Eq. (4) is the spectral acceleration hazard (i.e., the probability that the hazard level will exceed a particular value) determined from PSHA. The seismic risk of the structure can be then readily obtained by multiplying the fragility function by hazard function and calculating the integral in Eq. (4). The computational procedure is depicted in Figure 1 and explained in the next subsections.

\subsection{Estimation of spectral acceleration hazard}

The spectral acceleration hazard is estimated from PSHA of the study region. The methodology proposed by Das et al. [13] is adopted here for PSHA. Seismicity within $300 \mathrm{~km}$ radius from the site is considered. In general, PSHA provides the probability of exceedance of a strong ground motion parameter at a site due to all the earthquakes expected to occur during a specified exposure period. Here, we have considered PseudoSpectral Velocity, PSV(T), as a function of time period, $T$, as the ground motion parameter. The annual

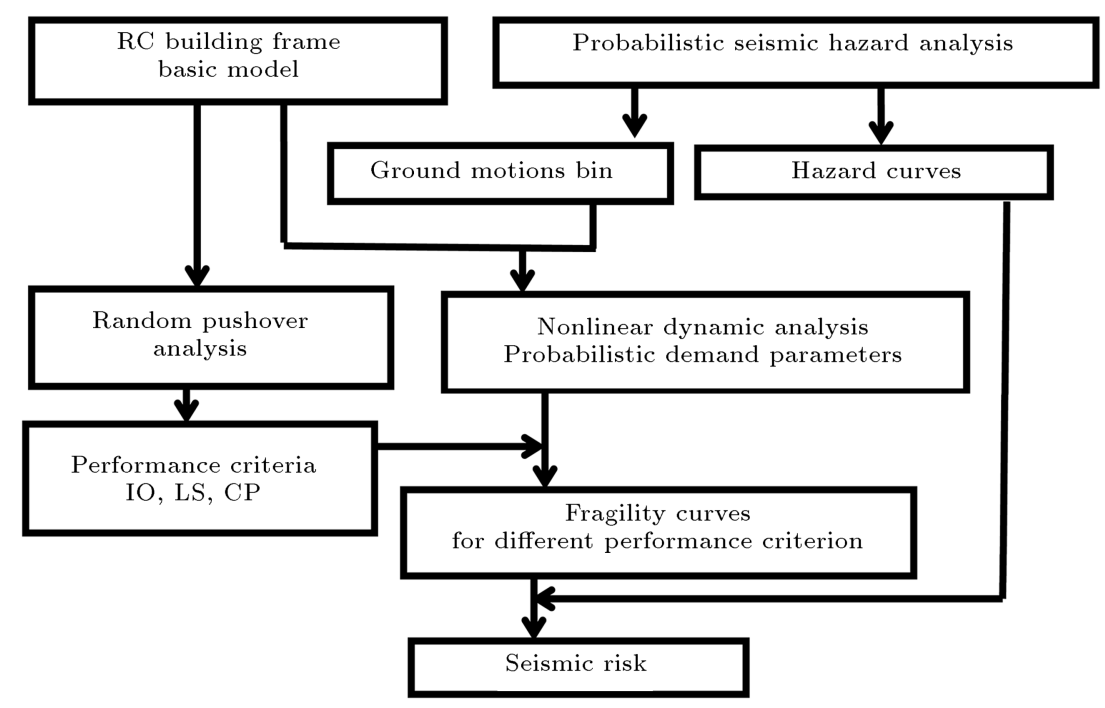

Figure 1. Overview of analytical seismic risk assessment. 
average occurrence rate of earthquakes, $\lambda(z)$, is then obtained as follows:

$$
\lambda(z)=\sum_{i=1}^{I} \sum_{j=1}^{J} q\left(z \mid M_{j} R_{i}\right) n\left(M_{j} R_{i}\right),
$$

where $q\left(z \mid M_{j} R_{i}\right)$ denotes the probability that a given $\operatorname{PSV}(\mathrm{T})$ of amplitude ' $z$ ' at a site will exceed during an event of magnitude $M_{j}$ occurring at a distance $R_{i}$. Computation of $q\left(z \mid M_{j} R_{i}\right)$ requires an attenuation model. There are several studies on attenuation model for this part of India and an excellent review for peak ground motion predictions for rock sites in India is worth mentioning [14] in this regard. For the present study, the attenuation model proposed by Das et al. [13] is adopted.

Quantity $n\left(M_{j} R_{i}\right)$ in Eq. (6) is the annual rate of occurrence of $\left(M_{j}, R_{i}\right)$ event. As the magnitude and distance are both continuous variables, they are discretized into small intervals for practical applications. In the present study, the magnitudes ranging from 4.0 to 8.5 are discretized into nine intervals with $\Delta M=0.5$. The epicentral distance within $300 \mathrm{~km}$ from the site is divided into 50 annular segments equally spaced in logarithmic scale. $M_{j}$ and $R_{i}$ denote the central values of each magnitude and distance range, respectively. We have estimated $\operatorname{PSV}(\mathrm{T})$ amplitudes for a particular combination of $M_{j}$ and $R_{i}$ as $\log \left[\operatorname{PSV}^{\prime}(T)\right]+\varepsilon(T)$, where $\varepsilon(T)$ is the error residual term obtained from the attenuation model. Assuming that the error residuals are normally distributed, the probability that the estimated value $\operatorname{PSV}^{\prime}(T)$ will be greater than specific value ' $z$ ' is obtained from the CDF of the error residuals:

$$
p(\varepsilon(T))=\frac{1}{\sigma(T) \sqrt{2 \pi}} \int_{-\infty}^{\varepsilon(T)} e^{-\frac{1}{2}\left(\frac{z-\mu(T)}{\sigma(T)}\right)^{2}} d x .
$$

Thus, the term $q\left(z \mid M_{j} R_{i}\right)$ is calculated as $1-p(\varepsilon(T))$. Assuming that $\lambda(z)$ is the average occurrence rate of a Poisson process, the probability of exceeding $z$ during an exposure period of $Y$ years is obtained from the following equation:

$$
P[\operatorname{PSV}(T)>z]=1-\exp \{-\lambda(z) . Y\} .
$$

In the present study, an exposure period of 50 years is considered to calculate the cumulative probability in Eq. (8). Based on the above outlined procedure, the PSV hazard curve is obtained. Now, to obtain the corresponding PSA hazard curve, we have multiplied the PSV ordinate by $2 \pi / T$. The earthquake catalogue used to obtain $n\left(M_{j} R_{i}\right)$ values contains information on 3071 past earthquake events covering periods from 1458 to 2000 within the geographical area between $18^{\circ}$ to $33^{\circ}$ latitude, $85^{\circ}$ to $100^{\circ}$ longitude. The annual occurrence rate of earthquakes, $n\left(M_{j} R_{i}\right)$, is obtained by spatially distributing the seismicity calculated from GutenbergRichter relationship. The detail of the procedure followed here is well explained in Das et al. [13].

Figure 2(a) shows the PSA hazard curve (in terms of ' $g$ '), thus obtained for horizontal motions, for $T=1.0 \mathrm{sec}$, and $Y=50$ years. Following the same procedure, hazard curves of different time periods are obtained. Uniform Hazard Spectrum (UHS) is then readily obtained by plotting the spectral acceleration values corresponding to a particular probability of exceedance (10\% herein) of the hazard curves for different time periods. Figure 2(b) shows the UHS obtained for Guwahati city for $10 \%$ probability of exceedance in 50 years. For analytical solution of fragility function, it is advantageous to approximate the hazard curve in the region of interest by a power law relationship [10]:

$$
\begin{gathered}
\lambda_{I M}(x)=P[I M \geq x]=1-\exp \left[-(x / u)^{-k}\right] \\
\approx(x / u)^{-k} \approx k_{0} x^{-k},
\end{gathered}
$$

where $u$ is the scale parameter, $k$ is the shape parameter, and constant $k_{0}=u^{k}$. The slope and intercept of the tangent of the hazard curve (Figure 2(a)) at point corresponding to $p=0.1, Y=50$ years provide the values of parameters $k_{o}$ and $k$. Thus, the power-law

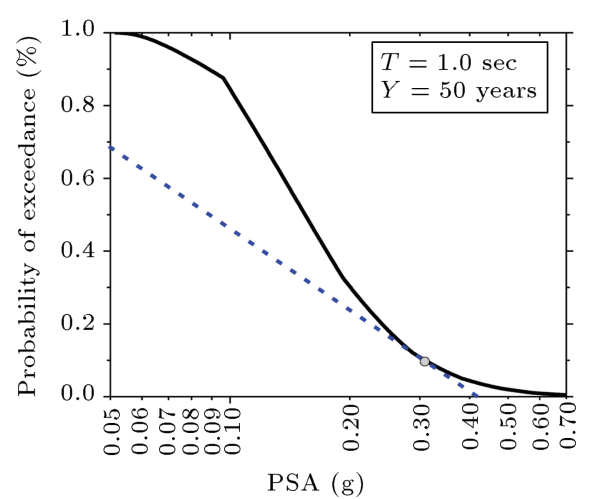

(a)

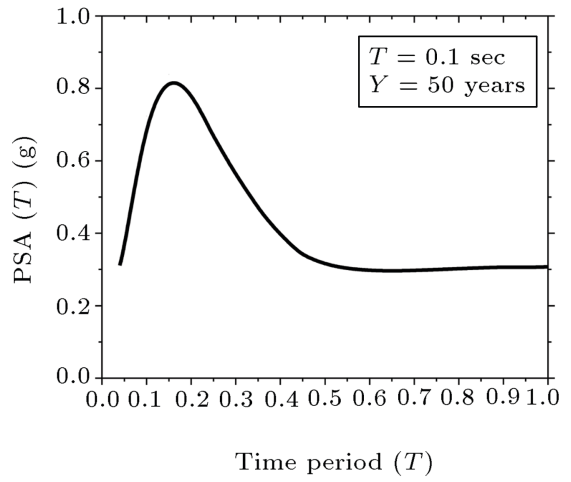

(b)

Figure 2. (a) Hazard curve for $T=1.0 \mathrm{sec}$ and exposure period of 50 years. (b) Uniform hazard spectra for $10 \%$ probability of exceedance in 50 years for Guwahati City. 
model of PSA hazard for Guwahati city is obtained as: $\lambda_{I M}(x)=0.0004 x^{-2.72}$ for $T=1.0 \mathrm{sec}, p=0.1$, and $Y=50$ years.

\subsection{Fragility function for a given ground motion intensity}

The fragility function can be developed by considering randomness in demand and capacity parameters. The conditional probability of seismic demand reaching or exceeding random structural capacity given a specific value of seismic intensity can be written as follows:

$$
F_{R}(x)=P\left[D \geq C \mid S_{a}=x\right] .
$$

For a given level of $S_{a}$, there will be variability in displacement-based demand due to randomness in the seismic excitation. A functional relationship between spectral acceleration and demand variable, specifically the median, $m_{D}$, of the demand, can be obtained. In general, the conditional median of $D$ for $S_{a}=x$ can be expressed as follows [11]:

$$
x_{D \mid S_{a}}(x)=g(x) .
$$

Assuming that the demand parameters are lognormally distributed, the above-conditional probabilistic model can be represented as follows:

$$
D=m_{D \mid S_{a}}(x) \cdot \varepsilon,
$$

where $\varepsilon$ is a lognormal random variable with a median equal to unity and conditional logarithmic standard deviation, $\sigma_{\ln \varepsilon}=\beta_{D \mid S_{a}}$. A power-law relationship, which conforms to both of our perception of structural performance and also helps reduce the analytical effort [11], can be constructed between the median demand and spectral acceleration as follows:

$$
m_{D \mid S_{a}}(x)=a \cdot x^{b}
$$

where ' $a$ ' and ' $b$ ' are the regression parameters to be obtained by probabilistic seismic demand analysis methods, e.g. cloud analysis, strip method, or incremental dynamic analysis method [11]. The cloud analysis is used in the present study, further of which is detailed in Section 5 .

Assuming that structural capacity is also lognormal with uncorrelated $D$ and $C$, following the fundamentals of the first-order reliability analysis method, the damage fragility can be obtained as follows:

$$
\begin{aligned}
F_{R}(x) & =\Phi\left[-\frac{\ln m_{C}-\ln m_{D \mid S_{a}}}{\sqrt{\beta_{C}^{2}+\beta_{D \mid S_{a}}{ }^{2}}}\right] \\
& =\Phi\left[\frac{\ln m_{D \mid S_{a}}-\ln m_{C}}{\sqrt{\beta_{D \mid S_{a}}^{2}+\beta_{C}^{2}}}\right] .
\end{aligned}
$$

Here, $F_{R}(x)$ is the fragility that the demand will reach or exceed the capacity for a specified value of $S_{a}=x$, $m_{C}$ is the median capacity, and $\beta_{C}$ is its lognormal SD. Substituting Eq. (13) in the above equation yields:

$$
\begin{aligned}
F_{R}(x) & =\Phi\left[\frac{\ln \left(a x^{b}\right)-\ln m_{C}}{\sqrt{\beta_{D \mid S_{a}}^{2}+\beta_{C}^{2}}}\right] \\
& =\Phi\left[\frac{\ln x-\ln \left(m_{C} / a\right)^{1 / b}}{\frac{1}{b} \sqrt{\beta_{D \mid S_{a}}^{2}+\beta_{C}^{2}}}\right] \\
& =\Phi\left[\frac{\ln \left(x / m_{R}\right)}{\beta_{R}}\right] .
\end{aligned}
$$

Eq. (15) represents the probability of failure for a given value of $S_{a}$ termed as damage fragility, where $m_{R}$ and $\beta_{R}$ are the median and dispersion of the damage fragility defined as follows:

$$
\begin{aligned}
& m_{R}=\left(m_{C} / a\right)^{1 / b}, \\
& \beta_{R}=\frac{1}{b} \sqrt{\beta_{D \mid S_{a}}^{2}+\beta_{C}^{2}},
\end{aligned}
$$

where:

$$
\beta_{C}=\sqrt{\beta_{C R}^{2}+\beta_{C U}^{2}} .
$$

It is to be noted that $\beta_{C}$ contains two components of uncertainty. Aleatory component, $\beta_{C R}$, is the result of structural uncertainty propagation obtained through capacity analysis of the considered structure for different performance levels. On the other hand, $\beta_{C U}$ arises due to uncertainty with regard to assumption of structural modelling. Due to non-availability of specific information on epistemic uncertainty, we have assumed a value of 0.2 for the present study [15].

\subsection{Seismic risk evaluation}

Once the conditional failure probability of seismic demand reaching or exceeding random structural capacity for a given value of $S_{a}$, i.e., $F_{R}(X)$, is obtained from Eq. (14), the seismic risk can be readily obtained. By substituting Eqs. (9) and (15) into Eq. (4) and carrying out the integration, failure limit state probability $P_{L S}$ can be obtained as:

$$
\begin{aligned}
P_{L S} & =P[D \geq C]=\sum_{x} P\left[D \geq C \mid S_{a}=x\right] \cdot P\left[S_{a} \geq x\right] \\
& =\int_{x} F_{R}(x) \cdot\left|d \lambda_{S_{a}}(x)\right|=\lambda_{I M}\left(m_{R}\right) \exp \left(\frac{1}{2} k^{2} \beta_{R}^{2}\right) \\
& =\lambda_{I M}\left(m_{R}\right) \exp \left[\frac{1}{2} \frac{k^{2}}{b^{2}}\left(\beta_{D \mid S_{a}}^{2}+\beta_{C}^{2}\right)\right] .
\end{aligned}
$$

These formulae for obtaining annual limit state probability can be directly used by substituting the values of $m_{R}$ and $\beta_{R}$ from Eq. (16) into Eq. (17) and the hazard curve given by Eq. (9). 


\section{Generation of ground motion database}

In the framework of PBEE, ground motion record is the most important input for proper evaluation of structural demand parameters through NLTHA. The current practice selects a suite of ground motion records whose intensities are exceeded with some specified probability at a given site and whose other properties typically determined by PSHA. Three options available for this are: recorded accelerograms from strong motion database; artificial accelerograms that match the target response spectra; and simulated accelerograms from theoretical modelling of fault rupture. The most acceptable form of SFA of structures employs recorded accelerograms. However, recorded accelerograms specific to the hazard level in the study region are limited. To augment the ground motion database, artificial and synthetic accelerograms are further generated identifying the most vulnerable combination of $M_{j}$ and $R_{i}$ for the specific hazard level to ensure the variability in the input ground motions. These are discussed in the following subsections.

\subsection{Natural accelerogram records}

The natural accelerograms recorded for rock site during past earthquakes in the region are selected. The selected records cover a magnitude range $\left(M_{w}\right)$ from 6.0 to 8.0 and epicentral distance within $300 \mathrm{~km}$ corresponding to the considered hazard level as identified from disaggregation of PSHA. For disaggregation study, a target hazard level is identified and contribution of each source is calculated by obtaining the probability of exceedance of the target hazard level for each of the sources [16] as follows:

$$
\begin{aligned}
P(M & \left.=M_{j}, R=R_{i} \mid \operatorname{PSV}(T) \geq z\right) \\
& =\frac{\lambda\left(\operatorname{PSV}(T)>z, M=M_{j}, R=R_{i}\right)}{\lambda(\operatorname{PSV}(T)>z)},
\end{aligned}
$$

where $P\left(M=M_{j}, R=R_{i} \mid \operatorname{PSV}(T) \geq z\right)$ is the probability that an earthquake of magnitude $M_{j}$ occurring at distance $R_{i}$ exceeds the target hazard level. The target hazard level is identified from UHS as $0.3 \mathrm{~g}\left(S_{a}\right.$

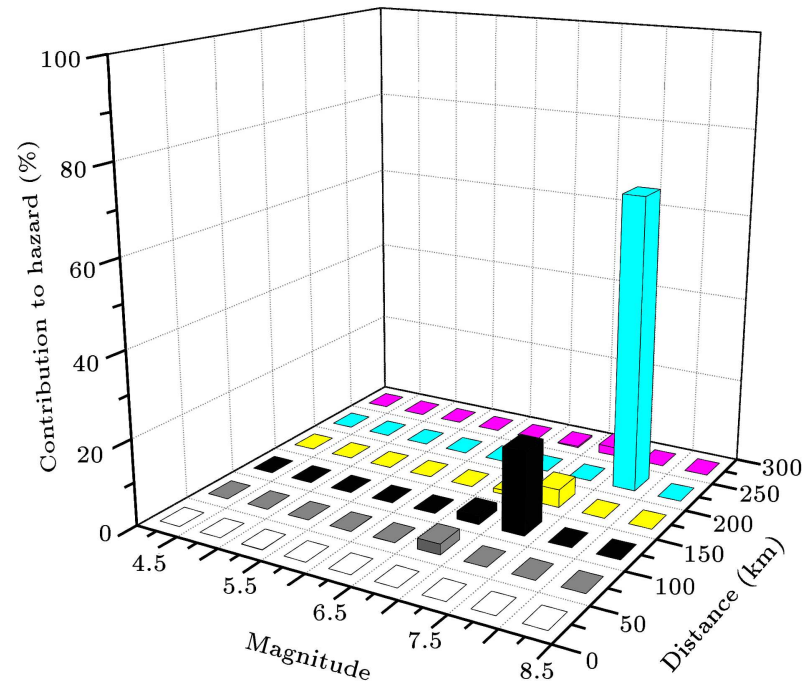

Figure 3. Results of disaggregation study for Guwahati City for $S_{a}$ at $T=1.0 \mathrm{sec}, P=0.1$, and $Y=50$ years.

at the fundamental period of the considered frame). Eventually, the annual occurrence rate as defined by the numerator of the right-hand side of Eq. (18) refers to the values of the probability term, $q\left(z \mid M_{j} R_{i}\right)$, in Eq. (6), and the denominator is the sum of all these probabilities. These values are already obtained in PSHA for all the considered magnitude and epicentral ranges. Figure 3 shows the results of disaggregation study for Guwahati city.

Due to limited recorded accelerograms in the region, accelerograms from northern Himalayan earthquakes are also included. We have excluded the earthquakes with epicentral distance within $10 \mathrm{~km}$ to avoid possible directivity pulse effect. Table 1 lists the details of the selected accelerograms available at COSMOS virtual data centre (http:// strongmotioncenter.org/vdc/scripts/defaul t.plx).

\subsection{Spectrum compatible accelerograms}

Artificial accelerograms are generated by matching the acceleration response spectra for rock hard soil site with 5\% damping factor as recommended by Bureau of Indian Standard [3]. Following Gasparini and Vanmarcke [17], stationary stochastic process is

Table 1. Selected accelerograms records.

\begin{tabular}{ccccccccc}
\hline Name & $\begin{array}{c}\text { Event } \\
\text { date }\end{array}$ & Station & Comp. & $\begin{array}{c}\text { Mag. } \\
(\mathbf{M s})\end{array}$ & $\begin{array}{c}\text { Dist. } \\
(\mathbf{k m})\end{array}$ & $\begin{array}{c}\text { Depth } \\
(\mathbf{k m})\end{array}$ & $\begin{array}{c}\text { Site } \\
\text { geology }\end{array}$ & $\begin{array}{c}\text { PGA } \\
(\mathbf{g})\end{array}$ \\
\hline Indo-burma Border & 6 Aug., 1988 & Baigao & S28W & 7.2 & 230 & 90 & Soft rock & 0.217 \\
Indo-burma Border & 6 Aug., 1988 & Berlongfer & N14W & 7.2 & 201 & 90 & Soft rock & 0.337 \\
Indo-burma Border & 8 May, 1997 & Jellalpur & N02E & 6.0 & 24 & 34 & Soft rock & 0.136 \\
Indo-burma Border & 8 May, 1997 & Katakhal & S01W & 6.0 & 40 & 34 & Soft rock & 0.159 \\
Uttarkashi, India & 19 Oct., 1991 & Bhatwari & N85E & 7.0 & 53 & 10 & Rock & 0.248 \\
Uttarkashi, India & 19 Oct., 1991 & Uttarkashi & N75E & 7.0 & 31 & 10 & Rock & 0.304 \\
Chamoli, India & 28 Mar., 1999 & Gopeswar & N20E & 6.6 & 14 & 15 & Rock & 0.353 \\
Chamoli, India & 28 Mar., 1999 & Ukhimath & N75W & 6.6 & 29 & 15 & Rock & 0.091 \\
\hline
\end{tabular}




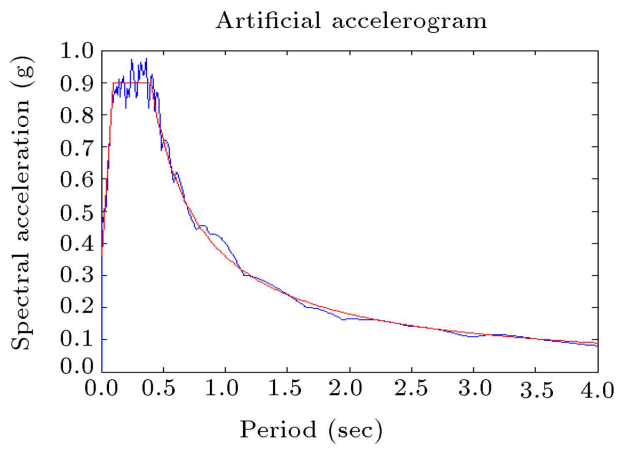

(a)

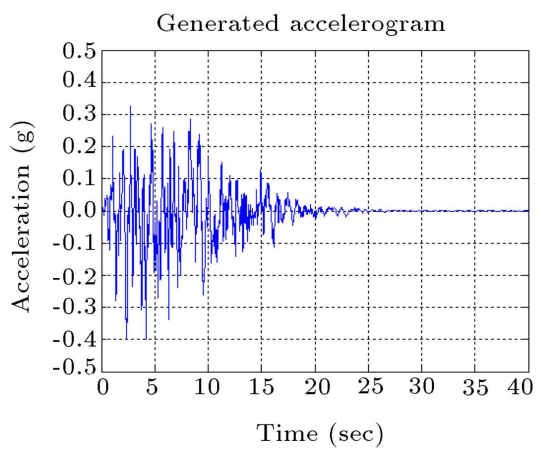

(b)

Figure 4. (a) Spectrally-matched ordinates of generated accelerogram. (b) Typical generated accelerogram by spectral matching.

obtained with the same general aspect but with different characteristics though by defining a vector of amplitudes and simulating different arrays of phase angles. These amplitudes are calculated using the Power Spectral Density (PSD) and the random phase angles are generated in the interval of 0 to $2 \pi$. The PSD function as proposed by Kaul [18] is adopted in this study. Further, to produce the transient nature of the earthquakes, the steady-state motions are multiplied by a deterministic envelope function [19]. This method of generating artificial accelerograms is iterative. For each cycle, the response spectrum generated for the simulated ground motion is compared with the target one (at a set of control frequencies). The ratio between the desired response and the computed response spectra is obtained at each cycle, and the corresponding PSD is recalculated as a function of the square of the aforementioned ratio. Using the modified PSD, another new accelerogram is simulated and a new response spectrum is obtained. The procedure is repeated with a new set of phase angles until the desired and computed response spectra converge. One such typical spectrallymatched ordinate and the corresponding accelerogram are shown in Figure 4.

\subsection{Generation of synthetic accelerograms}

The stochastic method as proposed by Boore [20] that combines parametric descriptions of amplitude spectrum with a random phase as a function of magnitude and distance from the source is considered in the present study for generation of synthetic accelerograms. This method is widely used to predict ground motions for regions where recordings of motion from potentially damaging earthquakes are scarce [21]. The Fourier amplitude spectrum of ground motion at a site is expressed as follows:

Ground motion $(f)=C \times$ Source $(f) \times$ Path $(f)$

$$
\times \text { Site }(f),
$$

where $C=R_{\theta \varphi} F H / 4 \pi \sigma \beta^{3}$ is the scaling factor in which $R_{\theta \varphi}$ represents the radiation pattern for a range of azimuths $\theta$ and take-off angles $\varphi ; F$ represents the free surface effect; and $H$ is the reduction factor that accounts for the partitioning of energy into two horizontal components. The crustal density and shear wave velocity are represented by $\alpha$ and $\beta$, respectively. By using $\omega$-square model [22], the source spectrum is obtained as:

$$
\text { Source }(f)=(2 \pi f)^{2} \frac{M_{0}}{\left[1+\left(f / f_{c}\right)^{2}\right]},
$$

where $M_{0}$ is seismic moment and corner frequency, $f_{c}$ is obtained from $f_{c}=4.9 \times 10^{6} \beta\left(\Delta \sigma / M_{0}\right)^{1 / 3}$ in which $f_{c}$ is in Hertz, $\beta$ is in $\mathrm{km} / \mathrm{s}$, the stress drop, $\Delta \sigma$, is in bars, and $M_{0}$ is in dyne-cm. The path term is defined in terms of the geometrical spreading (GSP) factor and the frequency-dependent quality factor $Q(f)$ and is given as follows:

$$
\text { Path }(f)=\operatorname{GSP}(r) \cdot e^{-\pi f r / Q(f) \beta} .
$$

The site term is defined in terms of frequencydependent amplification and diminution factor as:

$$
\text { Site }(f)=A(f) \times D(f)
$$

where $A(f)$ represents the site amplification. The diminution factor $D(f)$ is given by $D(f)=e^{\left(-\pi k_{0} f\right)}$, where $k_{0}$ is the distance-independent high frequency attenuation operator (Kappa factor). Three widely used techniques for estimation of site amplification are: Standard Spectral Ratio (SSR), generalised inversion (GINV), and Horizontal to Vertical Spectral Ratio (HVSR) [23]. The use of SSR method requires a reference rock site station; for GINV method, sites with known site responses are required [23]. As the stochastic model requires knowledge of many parameters related to source, site, and path characteristic, a detailed exploration of all the alternatives to achieve those will be extensive. With the readily available information, we found HVSR method as a practical alternative for site-response estimation. Thus, amplification function, $A(f)$, is estimated from HVSR. 
Table 2. The parameters adopted for synthetic ground motion generation.

\begin{tabular}{ccc}
\hline Parameters & Values & References \\
\hline Stress Drop $(\Delta \sigma)$ & $250 \mathrm{bars}$ & Raghukanth and Somala [21] \\
Quality Factor $\left(Q_{f}\right)$ & $224 f^{0.93}$ & Raghukanth and Somala [21] \\
Geometrical spreading factor $(\mathrm{GSP})$ & $1 / r$ for $r<100 \mathrm{~km}, 1 / 10 \sqrt{ } r$ for $r>100 \mathrm{~km}$ & Singh et al. [24] \\
Distance-dependent factor $(b)$ & 0.05 & Boore [20] \\
Shear wave velocity $(\beta)$ & $3.6 \mathrm{~km} / \mathrm{sec}$ & Mitra et al. [25] \\
Crustal density $(\sigma)$ & $2900 \mathrm{~kg} / \mathrm{m}^{3}$ & Chandler et al. [26] \\
kappa factor $\left(k_{0}\right)$ & $\left(0.057 / V_{s, 30}^{0.8}\right)-0.02$ & Chandler et al. [26] \\
V $s 30$ & $1.97 \mathrm{~km} / \mathrm{s}$ & Boore [20] \\
Reduction Factor $(\mathrm{H})$ & $1 / \sqrt{ } 2$ & Boore [20] \\
Radiation pattern $\left(R_{\theta \phi}\right)$ & 0.55 & Boore [20] \\
Free surface amplification $(\mathrm{F})$ & 2.0 & .
\end{tabular}

However, the site response should be studied further to explore the available alternatives.

The disaggregation study reveals that earthquakes between magnitudes $\left(M_{w}\right) 6.0$ to 8.0 have major contribution to the estimated hazard level. Strong motion data for Guwahati is very limited and most of which are not complying with the magnitude-distance range estimated from the PSHA disaggregation. Thus, Loharghat station is selected as the representative station which is closest to the Guwahati. In this regard, it may be noted that one earthquake record satisfying the above criteria is available for Guwahati, i.e., Bhutan earthquake (2009) having $M_{w}=6.2$ and epicentral distance of $126 \mathrm{~km}$. There are also recording stations operated by IIT, Guwahati which are not publicly available. Those may be considered for realistic HVSR analysis. However, this needs further study. In COSMOS virtual database, only one earthquake record is available for Loharghat station, which corresponds to the Indo-Burma Border earthquake (August, 1988). The three orthogonal components of the ground motion of this record are used to calculate HVSR. Fourier spectra of these three components are calculated and smoothed. Smoothed Fourier spectrums of two horizontal motions are then averaged using a quadratic mean. The average spectrum is divided by the smoothed vertical spectrum to get the HVSR. The HVSR when multiplied by the near-surface attenuation term, $e^{\left(-\pi k_{0} f\right)}$, gives the overall site amplification [21].

With the knowledge of the HVSR and the Fourier amplitude for stochastic point source model, synthetic accelerogram generation is straight forward. So, white Gaussian noise is generated with zero mean and unit $\mathrm{SD}$ and filtered to retain the frequencies between 0 to $50 \mathrm{~Hz}$. The filtered Gaussian noise is then windowed by the envelope function [19]. This windowed noise is Fourier transformed and normalized with its root mean square value. The normalized ordinates of the Fourier amplitudes are then multiplied by the Fourier amplitude of the ground motion model. The inverse Fourier transform of this Fourier spectrum gives the accelerogram in time domain. Following this procedure, eight accelerograms are generated for different magnitudes between $M_{w} 6.0$ to 8.0 and epicentral range within $300 \mathrm{~km}$. Table 2 summarizes various parameters used for the ground motion simulations and the specific values adopted in the present study along with useful references. Figure 5(a) compares the actual and typical simulated acceleration spectra at Loharghat Station. Figure 5(b) depicts the synthetic accelerogram generated for $M_{w}=6.0, R=150 \mathrm{~km}$, and focal depth $=15 \mathrm{~km}$.

\section{Case Study: A seven-storey RC frame}

\subsection{Description of the representative frame}

A seven-storey RC framed building considered to be located in Guwahati city of NE India and designed according to Indian codes is considered for numerical elucidation of the analytical seismic risk assessment. The building consists of three bays of $4.0 \mathrm{~m}$ width in the longitudinal direction and $5 \mathrm{~m}$ width in the transverse direction. A transverse 2-D frame is extracted from the building for the analysis (Figure 6(a)). The dead load consists of self-weight of structural and nonstructural members. The live load is assumed to be $1.5 \mathrm{kN} / \mathrm{m}^{2}$ for roof (accessible) and $3.0 \mathrm{kN} / \mathrm{m}^{2}$ for floors. The building frame is first analyzed by response spectrum method, following specifications given by BIS [3] with the following input parameters: Zone (V), importance 


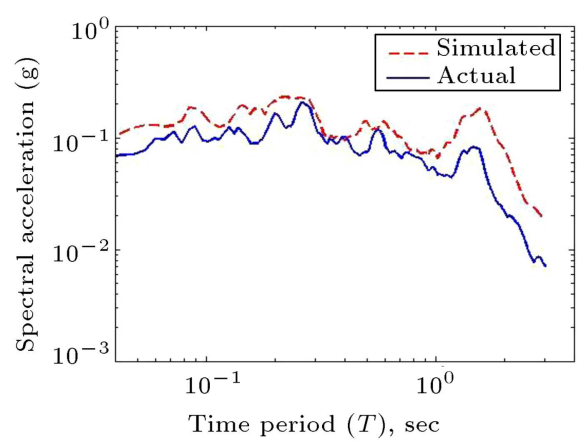

(a)

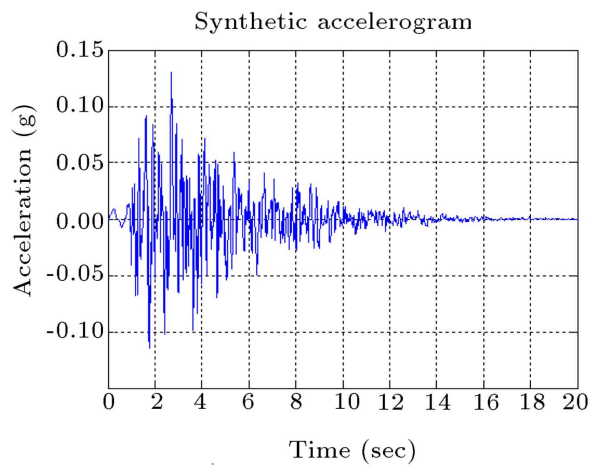

(b)

Figure 5. (a) Acceleration spectra for actual and simulated accelerograms of Loharghat station. (b) Generated accelerogram from the modified Fourier spectrum.

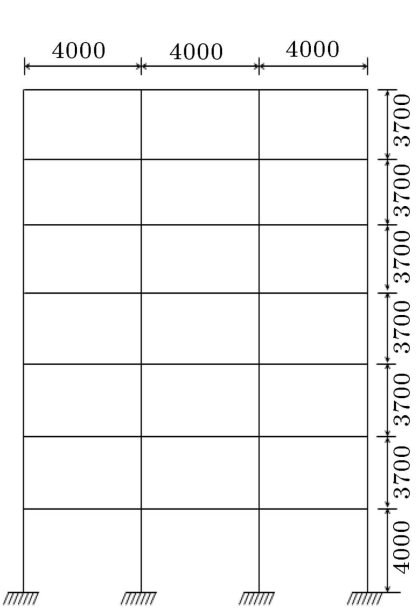

(a)

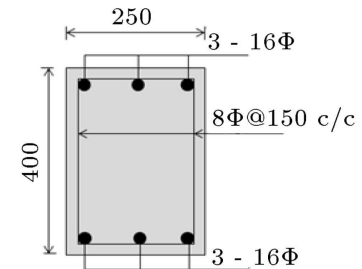

(b)

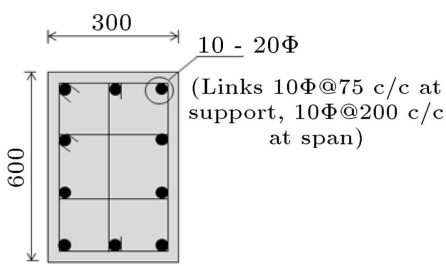

(d)

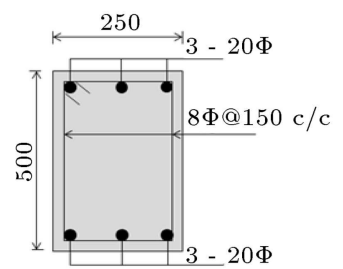

(c)

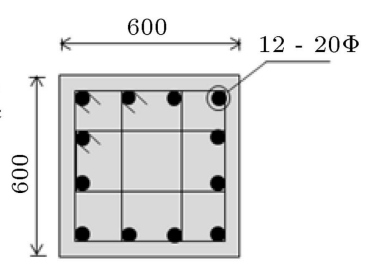

(e)

Figure 6. (a) The elevation of considered building frame. (b) Section of roof beams. (c) Section of floor beams. (d) Section of outer columns, (e) Section of inner columns.

factor $(\mathrm{I})$ of 1.0, response reduction factor $(\mathrm{R})$ of 5.0 (SMRF), and soil type (hard soil site, and spectral acceleration $\left(S_{a}\right)$ for $5 \%$ damped spectra). The concrete grade is considered as $M_{25}$ (i.e., compressive strength of concrete is $25 \mathrm{~N} / \mathrm{mm}^{2}$ ). The reinforcing steel grade is taken as HYSD500 (i.e., yield strength of steel is $500 \mathrm{~N} / \mathrm{mm}^{2}$ ). From the modal analysis, the time period of the structure at the fundamental mode is found to be 1.07 sec. All the peak response quantities for various modes are combined as per the Complete Quadratic Combination (CQC) rule [3]. The reinforcement and geometric dimension details of the beam and column sections are shown in Figure 6(b) to (e).

\subsection{Nonlinear time history analysis}

The nonlinear responses of the structure are calculated by NLTHA using SAP2000 software considering the accelerograms as described in Section 4. The stressstrain characteristics of concrete beams and columns are considered as per Mander's model [27]. For reinforcing steel, simple stress-strain model with isotropic strain-hardening behaviour is adopted. These stress strain models of concrete and steel are available in the SAP2000 software. The beams and columns are modelled with lumped plasticity model. For this purpose, the nonlinear hinges are assigned at the beam and column ends. The beams are modelled with moment hinges (M3), whereas the columns are modelled with axial-moment (P-M3) interacting hinges. Auto hinges are assigned according to the tables of FEMA 356 [28]. The NLTHA is carried out by Hilbert-Huges-Taylor (HHT) integration scheme [29]. From the NLTHA, the maximum Inter Storey Drift (ISD) values are obtained for the ground motion records, representing the structural demands $D$.

\subsection{Cloud analysis for estimation of demand parameters}

The power-law relationship between the median maximum ISD and spectral acceleration values (Eq. (13)) involves two regression parameters ' $a$ ' and ' $b$ ', which are obtained from the cloud analysis. The set of 
Table 3. Properties of the random structural parameters.

\begin{tabular}{ccccc}
\hline Uncertainty sources & Random variable & Mean & COV & Distribution type \\
\hline Dead load & Unit weight & $25 \mathrm{kN} / \mathrm{m}^{3}$ & 0.07 & Normal \\
Live load & Intensity of load, $q_{\text {live }}$ & $3 \mathrm{kN} / \mathrm{m}^{2}$ & 0.41 & Gamma \\
Grade M25 concrete & Characteristic compressive strength, $f_{c k}$ & $25 \mathrm{~N} / \mathrm{mm}^{2}$ & 0.21 & Lognormal \\
Grade Fe 500 steel & Characteristic yield, strength $f_{y}$ & $500 \mathrm{~N} / \mathrm{mm}^{2}$ & 0.07 & Lognormal \\
\hline
\end{tabular}

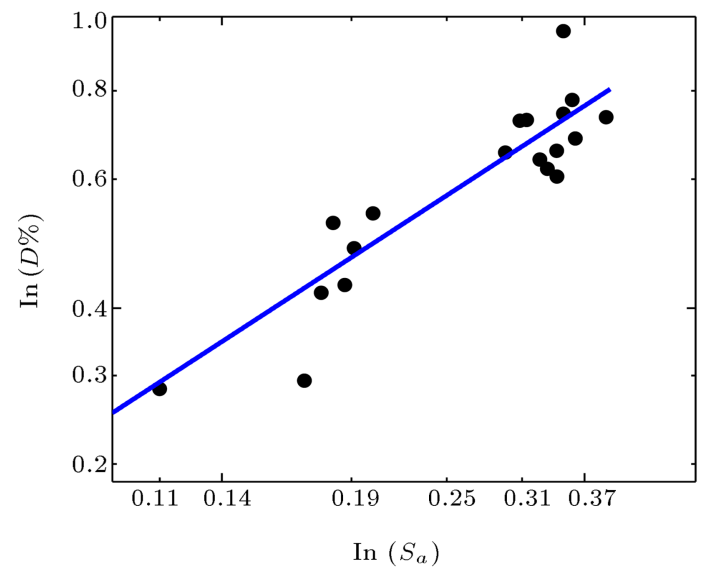

Figure 7. Cloud analysis through demand values.

ISD values obtained from the NLTHA for each of the ground motion records of the bin forms the basis of cloud analysis. In order to estimate the statistical properties of the "cloud" response, conventional linear regression is applied to the cloud of response values in the natural logarithmic scale. This results in a relation that predicts the median drift demand for a given level of spectral acceleration:

$$
\ln m_{D}=\ln a+b \cdot \ln \left(S_{a}\right) .
$$

The logarithmic SD of the regression measuring the second moment of the data points around the predicted curve gives the estimate of dispersion measure $\beta_{D \mid S_{a}}[11]:$

$$
\beta_{D \mid S_{a}}=\sqrt{\frac{\sum\left(\ln d_{i}-\ln \left(a . S_{a}^{b}\right)\right)^{2}}{n-2}} .
$$

From the NLTHA of the frame with twenty-four accelerograms, the cloud analysis is performed as shown in Figure 7 . The power-law relationship between the median demand and spectral acceleration is then given by:

$$
m_{D}\left(S_{a}\right)=1.713 . S_{a}^{0.828}, \quad \beta_{D \mid S_{a}}=0.263 .
$$

\subsection{Probabilistic seismic capacity analysis}

The Random Pushover Analysis (RPA) is used to obtain the probabilistic seismic capacity of the considered frame. For the present study, four structural parameters are considered to be random as listed in Table 3.

With the assumed distribution types of the structural parameters, 100 random samples are generated using Latin Hypercube Sampling (LHS) with reduced correlation. To reduce the correlation among the various parameters, the correlation reduction technique in transformed variable space [30] is adopted. Using the 100 generated sets of random parameters, the pushover analysis is performed. The maximum ISD values are calculated corresponding to each limit state considering the square root of the sum of the squares distribution method for lateral load distribution pattern. Rather than conventional roof displacement versus base shear curve, the pushover curve plots maximum ISD values versus base shear since the pushover analysis is applied to obtain the median capacity values $\left(m_{C}\right)$ and associated SD $\left(\beta_{C R}\right)$.

As per FEMA 356 [28], the three structural limit states or performance levels, namely the Immediate Occupancy (IO), Life Safety (LS), and Collapse Prevention $(\mathrm{CP})$, are considered in the present study. The IO level corresponds to the post-earthquake damage state with the occurrence of very limited structural damage. It is identified as the point in the pushover curves where the first yield deformation occurs. The LS performance level is defined as the post-earthquake damage state in which significant damage to the structure has occurred, but some margin against either partial or total structural collapse remains. It is considered to be the deformation corresponding to 0.75 times the deformation at the CP level [28]. The CP performance state means the post-earthquake damage state in which the building is on the verge of partial or total collapse. The CP limit state is identified from the pushover curve as the deformation $\left(\theta_{c}\right)$ corresponding to the peak shear resistance of the structure [28]. Figure 8 shows the median pushover curve, thus obtained with the median capacity values $\left(m_{C}\right)$ and the associated $\operatorname{SD}\left(\beta_{C R}\right)$ obtained for each limit state.

\subsection{Fragility curves and seismic risk evaluation}

The various parameters required for fragility curve and seismic risk evaluation are summarized in Table 4. With these parameters, the fragility curves corresponding to all the three limit states (i.e., IO, LS, and CP) are 
Table 4. The various parameters for obtaining fragility curves.

\begin{tabular}{|c|c|c|c|c|c|c|c|c|c|c|}
\hline \multirow[t]{2}{*}{ Limit states } & \multirow[t]{2}{*}{ IM } & \multicolumn{2}{|c|}{ PSHA } & \multicolumn{3}{|c|}{ CA } & \multicolumn{2}{|c|}{ RPA } & \multicolumn{2}{|c|}{ Damage fragility } \\
\hline & & $k_{0}$ & $k$ & $a$ & $b$ & $\boldsymbol{\beta}_{D \mid S_{a}}$ & $m_{C}$ & $\boldsymbol{\beta}_{C}$ & $\boldsymbol{m}_{R_{C}}$ & $\boldsymbol{\beta}_{\boldsymbol{R}_{C}}$ \\
\hline IO & $S_{a}$ & 0.004 & -2.72 & 1.713 & 0.828 & 0.263 & 0.54 & 0.20 & 0.25 & 0.40 \\
\hline LS & $S_{a}$ & 0.004 & -2.72 & 1.713 & 0.828 & 0.263 & 2.24 & 0.20 & 1.38 & 0.40 \\
\hline $\mathrm{CP}$ & $S_{a}$ & 0.004 & -2.72 & 1.713 & 0.828 & 0.263 & 3.00 & 0.22 & 1.96 & 0.42 \\
\hline
\end{tabular}

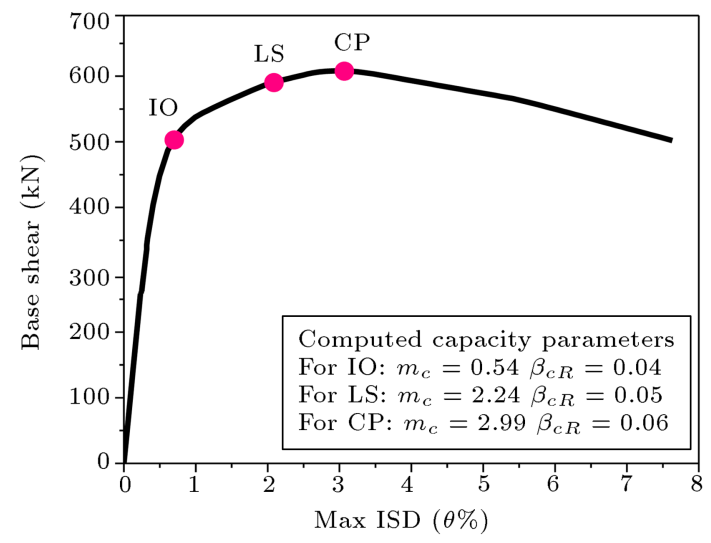

Figure 8. The median pushover curve and computed capacity parameters.

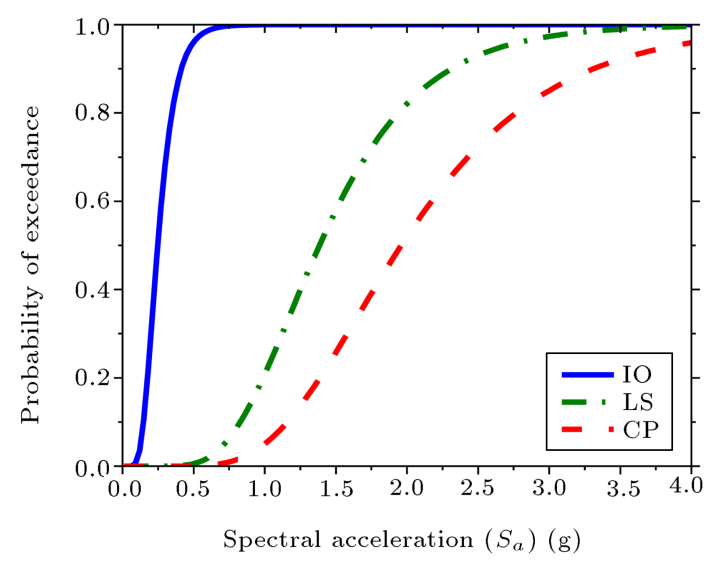

Figure 9. The seismic fragility curves corresponding to different limit states.

Table 5. The annual failure probability for different limit states.

\begin{tabular}{cc}
\hline Limit state & $\boldsymbol{P}_{\boldsymbol{L S}}$ \\
\hline IO & 0.06170 \\
LS & 0.00057 \\
CP & 0.00023 \\
\hline
\end{tabular}

obtained for the considered RC frame and are shown in Figure 9.

Using the fragility and hazard curves, the annual failure probabilities corresponding to the spectral acceleration hazard level of $10 \%$ probability of exceedance in 50 years for different limit states are calculated. Table 5 lists the estimated annual failure probabilities.

\section{Summary and conclusions}

The analytical SFA of RC framed building located in Guwahati city, NE India is presented in the framework of PBEE for different limit states, namely IO, LS, and $\mathrm{CP}$. The following observations are made:

1. From the NLTHA of the RC frame, the computed maximum inter-storey drift demands obtained for the spectrally-matched accelerograms are relatively higher than those obtained from the natural or synthetically generated accelerograms;

2. The synthetic accelerograms are able to capture the inherent randomness of the recorded accelerograms to a great extent and yield more realistic drift response of the structure than the spectrally-matched one when compared to the responses obtained for natural recorded accelerograms;

3. The estimated fragility curves show that the structure is associated with high probability of failure (almost 60\%) for IO limit state corresponding to the spectral acceleration hazard level at the fundamental periods of the structure. However, for LS and CP limit states, the performance of the structure is rather satisfactory. At this hazard level, the structure shows relatively high risk of annual failure (about 6\%) for IO limit state, whereas the annual failure probability is much less for LS and CP limit states.

Based on those observations, it may be opined that a medium-rise RC framed building located in the study area with moderate fundamental period, when designed according to the guidelines of IS codes, is most likely to perform beyond its elastic range (i.e., beyond IO level) when subjected to the prevalent hazard level identified in this study. However, the reinforcement provided as per ductility-based detailing is sufficient enough to prevent life-threatening risk and/or complete collapse of the structure. The analytical seismic risk assessment procedure presented here is generic in nature and can be readily applied to other building typologies located in the region.

\section{Acknowledgement}

The financial support received in TSD Scheme No. 
DST/TSG/STS/2012/45, 21.1.13 from the DST, Govt. of India (for the project entitled "Seismic vulnerability assessment of existing buildings to supplement rehabilitation practices with special emphasis to North Eastern Region") in connection with this work is gratefully acknowledged.

\section{References}

1. Günay, S. and Mosalam, K.M. "PEER performancebased earthquake engineering methodology, revisited", Journal of Earthquake Engineering, 17(6), pp. 829-858 (2013).

2. Talukdar, P. and Barman, N.C. "Seismic activity and seismotectonic correlation with reference to northeast India", IOSR Journal of Applied Physics, 2(2) (2012).

3. BIS. "IS 1893 (Part 1) - Indian standard criteria for earthquake resistant design of structures, part 1: general provisions and buildings (fifth revision)", Bureau of Indian Standards, New Delhi (2002).

4. Bhatia, S.C., Ravi Kumar, M. and Gupta, H.K. "A probabilistic seismic hazard map of India and adjoining regions", Annals of Geophysics, 42(6), pp. 1153-1164 (1999).

5. Nath, S.K. and Thingbaijam, K.K.S. "Probabilistic seismic hazard assessment of India", Seismological Research Letters, 83(1), pp. 135-149 (2012).

6. Lu, D., Yu, X., Jia, M. and Wang, G. "Seismic risk assessment for a reinforced concrete frame designed according to Chinese codes", Struct. and Infrastruct. Eng., 10(10), pp. 1295-1310 (2014).

7. Fragiadakis, M., Vamvatsikos, D., Karlaftis, M.G., Lagaros, N.D. and Papadrakakis, M. "Seismic assessment of structures and lifelines", J. of Sound and Vibration, 334, pp. 29-56 (2015).

8. Dymiotis, C., Kappos, A.J. and Chryssanthopoulos, M.K. "Seismic reliability assessment of RC frames with uncertain drift and member capacity", J. Struct. Eng. $A S C E$, 125(9), pp. 1038-1047 (1999).

9. Collins, K.R., Wen, Y.K. and Foutch, D.A. "Dual-level design: a reliability-based methodology", Earthq. Eng. and Struct. Dyna., 25(12), pp. 1433-1467 (1996).

10. Cornell, C.A., Jalayer, F., Hamburger, R.O. and Foutch, D.A. "The probabilistic basis for the 2000 SAC Federal Emergency Management Agency steel moment frame guidelines", ASCE J. of Struct. Eng., 128(4), pp. 526-533 (2002).

11. Jalayer, F. "Direct probabilistic seismic analysis: implementing non-linear dynamic assessments", PhD Thesis, Department of Civil and Env. Eng., Stanford, CA (2003).

12. Shome, N., Cornell, C.A., Bazzurro, P. and Caraballo, J.E. "Earthquakes, records, and nonlinear responses", Earthq. Spectra, 14(3), pp. 467-500 (1998).

13. Das, S., Gupta, I.D. and Gupta, V.K. "A probabilistic seismic hazard analysis of Northeast India", Earthq. Spectra, 22(1), pp. 1-27 (2006).
14. Nath, S.K. and Thingbaijam, K.K.S. "Peak ground motion predictions in India: an appraisal for rock sites", Journal of Seismology, 15(2), pp. 295-315 (2011).

15. Wen, Y.K., Ellingwood, B.R., Veneziano, D. and Bracci, J. "Uncertainty modeling in earthquake engineering", MAE Project FD-2 Report, Mid-America Earthquake Center, USA (2003).

16. McGuire, R.K. "Probabilistic seismic hazard analysis and design earthquakes: closing the loop", Bull. Seismol. Soc. Am., 85, pp. 1275-1284 (1995).

17. Gasparini, D.A. and Vanmarcke, E.H., SIMQKE, a Program for Artificial Motion Generation, User's Manual and Documentation, Publication R76-4, MIT Press, Cambridge, Massachusetts (1976).

18. Kaul, M.K. "Stochastic characterization of earthquakes through their response spectrum", Earthq. Eng. and Struct. Dyna., 6, pp. 497-509 (1978).

19. Saragoni, G.R. and Hart, G.C. "Simulation of artificial earthquakes", Earthq. Eng. and Struct. Dyna., 2, pp. 249-268 (1974).

20. Boore, D.M. "Simulation of ground motion using the stochastic method", Pure Appl. Geophys., 160, pp. 635-676 (2003).

21. Raghukanth, S.T.G. and Somala, S.N. "Modeling of strong-motion data in northeastern India: q, stress drop, and site amplification", Bulletin of the Seismological Society of America, 99(2A), pp. 705-725 (2009).

22. Brune, J. "Tectonic stress and the spectra of seismic shear waves from earthquakes", J. Geophys. Res, 75, pp. 4997-5009 (1970).

23. Nath, S.K. and Thingbaijam, K.K.S. "Assessment of seismic site conditions: a case study from Guwahati city, Northeast India", Pure Appl. Geophys., 168, pp. 1645-1668 (2011)

24. Singh, S.K., Ordaz, M., Dattatrayam, R.S. and Gupta, H.K. "A spectral analysis of the 21 May 1997, Jabalpur, India, earthquake (Mw 5.8) and estimation of ground motion from future earthquakes in the Indian shield region", Bulletin of the Seismological Society of America, 89(6), pp. 1620-1630 (1999).

25. Mitra, S., Priestley, K., Bhattacharyya, A.K. and Gaur, V.K. "Crustal structure and earthquake focal depths beneath northeastern India and Southern Tibet", Geophys. J. Int., 160, pp. 227-248 (2005).

26. Chandler, A.K., Lam, N.T.K. and Tsang, H.H. "Nearsurface attenuation modelling based on rock shearwave velocity profile", Soil Dyn. Earthq. Eng., 26, pp. 1004-1014 (2006).

27. Mander, J.B., Priestley, M.J.N. and Park, R. "Theoretical stress-strain model for confined concrete", $J$. 
Struct. Engin., ASCE, 114(8), pp. 1804-26 (1988).

28. Federal Emergency Management Agency (FEMA). "Prestandard and commentary for the seismic rehabilitation of buildings", Rep. No. 356 - FEMA, Washington, DC (2000).

29. Hilber, H.M., Hughes, T.J.R. and Taylor, R.L. "Improved numerical dissipation for time integration algorithms in structural dynamics", Earthquake Eng. and Struct. Dynamics, 5, pp. 283-292 (1977).

30. Olsson, J. and Sandberg, G.E. "Latin hypercube sampling for stochastic finite element analysis", J. of Eng. Mech. ASCE, 128(1), pp. 121-125 (2002).

\section{Biographies}

Swarup Ghosh is a doctoral student in the Department of Civil Engineering, Indian Institute of Engineering Science and Technology Shibpur, India. He completed his Bachelor of Engineering in Civil Engineering from Jalpaiguri Government Engineering College and Master of Engineering with specialization in Structural Engineering from Bengal Engineering and Science University, Shibpur. In general, Mr. Ghosh's research interest lies in the field of seismic hazard analysis, vulnerability assessment of existing structure, uncertainty modelling, etc.

Subrata Chakraborty is currently a Professor and the Head of Civil Engineering at Indian Institute of Engineering Science and Technology Shibpur, India. He is a fellow of the Indian National Academy Engineering and the Institution of Engineers (India). Professor Chakraborty completed his Bachelor of Engineering in Civil Engineering from Bengal Engineering College of Calcutta University and Master of Technology and Doctor of Philosophy in Civil Engineering with specialization in Structural Engineering from Indian Institute of Technology Kharagpur. He was a postdoctoral researcher at University of Cambridge in 2003, at University of Arizona in 2005, and at RWTH Aachen Germany in Alexander von Humboldt Fellowship in 2009 and 2010. In general, Professor Chakraborty's research interest lies in stochastic finite-element and stochastic sensitivity analysis, stochastic dynamic and seismic reliability analysis, health monitoring of structures, vibration control, reliability analysis of hybrid uncertain system, reliability based and robust optimization of structures. 